九州大学学術情報リポジトリ

Kyushu University Institutional Repository

\title{
CCAAT/enhancer binding protein $\beta$ regulates expression of matrix metalloproteinase-3 in arthritis
}

Tsushima, Hidetoshi

Department of Orthopaedic Surgery, Graduate School of Medical Sciences, Kyushu University

Okazaki, Ken

Department of Orthopaedic Surgery, Graduate School of Medical Sciences, Kyushu University

Hayashida, Mitsumasa

Department of Orthopaedic Surgery, Graduate School of Medical Sciences, Kyushu University

Ushijima, Takahiro

Department of Orthopaedic Surgery, Graduate School of Medical Sciences, Kyushu University

他

http://hdl. handle. net/2324/27286

出版情報: Annals of the Rheumatic Diseases. 71 (1), pp.99-107，2012-01. BMJ Publishing Group Ltd

バージョン :

権利関係: (C) BMJ Publishing Group Ltd \& European League Against Rheumatism 


\section{CCAAT/Enhancer Binding Protein $\beta$ Regulates Expression of Matrix}

\section{Metalloproteinase-3 in Arthritis.}

Hidetoshi Tsushima, M.D.

Ken Okazaki, M.D., Ph.D.

Mitsumasa Hayashida, M.D., Ph.D.

Takahiro Ushijima, M.D.

Yukihide Iwamoto, M.D., Ph.D.

Investigation performed at Department of Orthopaedic Surgery, Graduate School of Medical Sciences, Kyushu University, Fukuoka, Japan.

Correspondence should be sent to: Ken Okazaki. MD., PhD.

Department of Orthopaedic Surgery,

Graduate School of Medical Sciences,

Kyushu University,

3-1-1 Maidashi, Higashi-ku, Fukuoka 812-8582, Japan.

Tel: 81-092-642-5487 Fax: 81-092-642-5507

E-mail: okazaki@ortho.med.kyushu-u.ac.jp 


\begin{abstract}
Objectives: To investigate whether CCAAT/enhancer-binding protein $\beta(\mathrm{C} / \mathrm{EBP} \beta)$ mediates expression of matrix metalloproteinase-3 (MMP-3) and aggrecanases in arthritis.

Methods: Localization of C/EBP $\beta$ and MMP-3 in synovium and cartilage from rheumatoid arthritis and osteoarthritis patients was determined by immunohistochemistry. Cell lines, SW982, C28/I2 and human fibroblast-like synoviocytes stimulated by IL-1 $\beta$ were subjected to western blotting and quantitative polymerase chain reaction. Over-expression of C/EBP $\beta$ by adenovirus was performed in cells and organ culture of normal cartilage. Knockdown of C/EBP $\beta$ by small interference RNA was performed in cells. Activity of the human MMP-3 and aggrecanase-2 (ADAMTS-5) promoters was analyzed by a luciferase assay. To determine whether $\mathrm{C} / \mathrm{EBP} \beta$ directly binds to the MMP-3 or ADAMTS-5 promoter, a chromatin immunoprecipitation (ChIP) assay was performed.
\end{abstract}

Results: Immunohistochemistry showed that $\mathrm{C} / \mathrm{EBP} \beta$ and MMP-3 were co-localized in arthritic synovium and cartilage. Western blots revealed increased C/EBP $\beta$ expression in cells treated with IL-1 $\beta$. Expression of MMP-3, MMP-13, and ADAMTS-5 mRNA was significantly increased by the over-expression of C/EBP $\beta$. C/EBP $\beta$ stimulated MMP-3 expression and induced matrix degradation in cartilage explants. C/EBP $\beta$ knockdown reduced MMP-3 and ADAMTS-5 expression. C/EBP $\beta$ stimulated the 2011 bp MMP-3 promoter and the 1768 bp ADAMTS-5 promoter in a dose-dependent manner. Deletion and mutation analysis of the MMP-3 promoter revealed that the C/EBP $\beta$ core responsive element was located between $-108 \mathrm{bp}$ and $-100 \mathrm{bp}$. A ChIP assay showed that C/EBP $\beta$ directly bound to MMP-3 and ADAMTS-5 promoters.

Conclusions: These data demonstrate that $\mathrm{C} / \mathrm{EBP} \beta$ is involved in expression of MMP-3 and ADAMTS-5 in arthritic synovium and cartilage. 


\section{INTRODUCTION}

Irreversible destruction of cartilage is a feature of arthritis such as rheumatoid arthritis (RA) and osteoarthritis (OA). Inflammation pathways are involved in the catabolic processes of articular cartilage especially in RA and potentially in OA. Proinflammatory cytokines such as interleukin-1 $\beta$ (IL-1 $\beta$ ) and tumor necrosis factor $\alpha$ (TNF- $\alpha$ ) play significant roles in mediating inflammation and joint destruction and have been therapeutic targets. Although the levels of proinflammatory cytokines in OA are generally lower than those in RA [1], inflammatory reactions are associated with symptoms of OA especially in the early stages of the disease.[2] Stimulation of these cytokines in arthritis activates numerous transcriptional factors and induces expression of matrix metalloproteinases (MMPs), aggrecanases, and other catabolic factors in the synovium, synovial fluids and cartilage, which adversely affects the joint structures including cartilage.[3, 4]

Among transcriptional factors activated by proinflammatory cytokines, we focused on the functions of the CCAAT/enhancer binding protein $(\mathrm{C} / \mathrm{EBP})$ family in arthritis. The C/EBP family contains a basic leucine zipper domain and consists of six family members: $\mathrm{C} / \mathrm{EBP} \alpha, \beta, \delta, \varepsilon, \gamma$, and $\zeta .[5]$ Functions of the $\mathrm{C} / \mathrm{EBP}$ family include regulation of numerous cellular processes including differentiation, proliferation, control of metabolism, and inflammation. $\mathrm{C} / \mathrm{EBP} \beta$ and/or $\delta$ are induced in response to inflammatory stimulation in various tissues.[6] Previous reports describe that C/EBP $\beta$ and $\delta$ are expressed in synovial tissues of RA and OA.[7, 8] Recent reports suggest that C/EBP $\beta$ may act via three catabolic pathways during the development of arthritis. First, $\mathrm{C} / \mathrm{EBP} \beta$ directly enhances inflammatory enzymes. $\mathrm{C} / \mathrm{EBP} \beta$ and/or $\delta$ mediate inflammatory genes such as phospholipase A2 and cyclooxygenase-2 in articular cartilage.[9, 10] Second, C/EBP $\beta$ regulates extracellular matrix (ECM) synthesis. $\mathrm{C} / \mathrm{EBP} \beta$ and $\delta$ repress type I collagen [11] and activate osteocalcin in osteoblasts.[12] Also, C/EBP $\beta$ and $\delta$ induced by IL-1 $\beta$ mediate the repression of 
cartilage-derived retinoic acid-sensitive protein (CD-RAP) and Col2 $\alpha 1$ promoter activity in chondrocytes.[13] Third, C/EBP $\beta$ mediates the expression of catabolic enzymes in arthritis. MMP-1 is transactivated by C/EBP $\beta$ in chondrocytes through IL-1 $\beta$-stimulated extracellular signal regulated kinase (ERK) activation.[14] A previous report demonstrated that expression of MMP-13 is mediated by $\mathrm{C} / \mathrm{EBP} \beta$ in human chondrocytes in inflammatory arthritis.[15] These findings suggest that $\mathrm{C} / \mathrm{EBP} \beta$ and $\delta$ plays important roles in various catabolic processes in arthritis. Further analysis of the functions of C/EBP is important for understanding the pathogenesis of arthritis.

MMPs are known to be important factors in degrading native collagen and proteoglycans and leading to the development of arthritis. Aggrecanases, also known as A Disintegrin And Metalloproteinase with ThromboSpondin type 1 motifs (ADAMTS), are proteolytic enzymes that are responsible for cleavage of the proteoglycan aggrecan. In humans, aggrecanase-1 (ADAMTS-4) and aggrecanase-2 (ADAMTS-5) are considered to be major contributors to the development of OA.[16, 17] Matrix metalloproteinase 3 (MMP-3) is also highly expressed in synovial cells and chondrocytes of inflammatory arthritis.[18, 19] MMP-3 has a variety of substrate specificities and degrades proteoglycans, collagen types III, IV, IX and XI, gelatin, laminin, and fibronectin.[20] Furthermore, MMP-3 can activate procollagenases MMPs-1, -8, and -13.[21] When OA was experimentally induced in MMP-3 knock-out mice, there was a $67 \%$ reduction in the occurrence of severe cartilage damage when compared with control mice.[22] In clinical practice, serum levels of MMP-3 are used as a marker for predicting disease activity and progression in RA and potentially in OA.[23, 24] Thus, MMP-3 plays a pivotal role in the pathological destruction of cartilage in both RA and $\mathrm{OA}$.

In this paper, we investigated the functional involvement of $\mathrm{C} / \mathrm{EBP} \beta$ for regulating catabolic enzymes, specifically MMP-3 and ADAMTS-5, in synovium and 
cartilage. Manifestation of the mechanisms related to the regulation of proteolytic enzymes by activation of $\mathrm{C} / \mathrm{EBP} \beta$ may provide new insights into the development of potential therapies.

\section{MATERIALS AND METHODS}

Detailed methods are described in the online supplement.

Clinical samples. Tissue samples of articular cartilage and synovium were obtained from patients with RA and OA at the time of total knee arthroplasty (TKA). Subjects included 7 RA patients (mean age, $65.7 \pm 12.0$ years), who fulfilled the American College of Rheumatology (ACR) diagnostic criteria [25] for RA and 10 OA patients (mean age, $76.0 \pm$ 6.2 years). All studies were carried out under the approval of the University Institutional Ethics Board and in accordance with the Tenets of the Declaration of Helsinki.

Immunohistochemistry. Immunostaining was performed using primary antibodies for C/EBP $\beta$ (C-19; Santa Cruz Biotechnology, Santa Cruz, CA) diluted 1:1,000, C/EBP $\delta$ (M-17; Santa Cruz) diluted 1:500, MMP-3 (F-66; Daiichi Fine chemical, Toyama) diluted 1:200, and C-terminal aggrecan neoepitope VDIPEN and NITEGE antibodies, which were exposed following cleavage by MMPs and aggrecanases, respectively (both antibodies kindly provided by Dr. John S. Mort, Shriners Hospital for Children and McGill University), diluted 1:500.[26, 27]

Cell culture. The immortalized human chondrocyte cell line C-28/I2 was cultured in Dulbecco's modified Eagle's medium (DMEM)/Ham's F-12 medium supplemented with $10 \%$ fetal bovine serum (FBS) (Gibco, Gaithersburg, $\quad$ MD) and $1 \%$ ITS-(insulin-transferrin-selenium) Universal Culture Supplement Premix reagent (BD Biosciences, San Jose, CA). SW982 cells, a human synovial sarcoma cell line, were grown in RPMI 1640 culture medium containing 10\% FBS. Human fibroblast-like synoviocytes 
(HFLS) (Cell Applications, Inc, San Diego, CA) that were derived from normal synovial tissue were cultured in DMEM supplemented with 10\% FBS.

Western blotting. Whole cell extracts, nuclear or cytoplasmic extracts isolated from treated cells were assayed.

\section{Enzyme-linked immunosorbent assay (ELISA)}

Human MMP-3 and IL-6 in the conditioned medium of cells transfected with gene over-expression were detected via ELISA (R\&D Systems, Minneapolis, MN)

RNA extraction and real-time reverse transcription (RT)-PCR. Total RNA was extracted from cultured cells and quantitative real-time RT-PCR was performed with the LightCycler2.0 system (Roche) using SYBR Premix Ex Taq (Takara Bio, Shiga, Japan).

Transient transfection and gene over-expression in cell lines. Cells were transfected with an adenovirus expression vector for C/EBP $\beta$-LAP (36 kDa isoform) [28] or a $\mathrm{LacZ}$ control for 24 hours. To assess the activity of MMP-3 induced by C/EBP $\beta$, conditioned medium of cells transfected with adenovirus vector for C/EBP $\beta$-LAP or LacZ control for 72 hours was assayed by casein zymography using $12 \%$ casein zymogram gels (Invitrogen, Carlsbad, CA). Gene knockdown for cell lines. Pre-designed small interference RNA (siRNA) for C/EBP $\beta$ (siRNA-1 target sequence, 5'-CCCACGUGUAACUGUCAGCtt-3' [sense] and 5'-GCUGACAGUUACACGUGGGtt-3' [antisense]. siRNA-2 target sequence, 5'-GGCCCUGAGUAAUCGCUUAtt-3' [sense], 5'-UAAGCGAUUACUCAGGGCCcg-3' [antisense]) or negative control siRNA were purchased (Ambion). Transfection mixes were prepared using Lipofectamine RNAiMAX (Invitrogen) with control or target-specific siRNA and applied to cells. Cells were cultured for 24 hours after transfection. Transfected SW982,

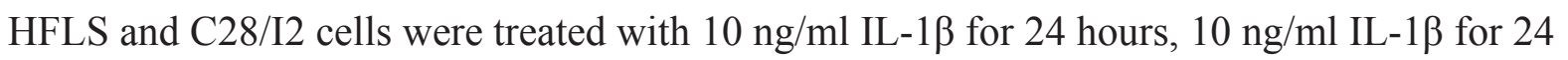
hours, and $2 \mathrm{ng} / \mathrm{ml} \mathrm{IL-1 \beta}$ for 5 hours, respectively. 
Human MMP-3 and ADAMTS-5 promoter reporter constructs. Promoter constructs for human MMP-3 and human ADAMTS-5 were generated by PCR and subcloned into the pGL-4.10 [luc2] vector (Promega, Madison, WI). The 5'-upstream region (-2011 bp) of the human MMP-3 gene was prepared using human genomic DNA as a template and then the -2011 bp MMP-3 promoter constructs ( $p$-full) and promoter deletion constructs ( $p$-del) were generated. There are 3 putative binding sites for C/EBP between - $224 \mathrm{bp}$ and - $56 \mathrm{bp}$. A 2 bp mutation $(\mathrm{m})$ was made at one site or at both sites $(\mathrm{Dm}=$ double mutation $)$ in the $\mathrm{p}$-del2 construct using the QuickChange site-directed mutagenesis kit (Stratagene, La Jolla, CA). A $2498 \mathrm{bp}$ fragment of the ADAMTS-5 promoter, containing sequences from -1768 to +730 relative to the transcriptional start site, was used as a template to PCR amplify the full-length promoter.

Plasmid transfection and luciferase assay. Cells seeded in 6-well plates were co-transfected with $0.6 \mu \mathrm{g} /$ well of a series of deletion constructs for the MMP-3 promoter or the -1768 bp ADAMTS-5 promoter construct and pCMV-LAP, an expression vector of rat $\mathrm{C} / \mathrm{EBP} \beta$-LAP directed by a cytomegalovirus promoter [29], or $\mathrm{pMSV}-\mathrm{C} / \mathrm{EBP} \delta$, an expression vector of rat $\mathrm{C} / \mathrm{EBP} \delta$ [30] using Lipofectamine 2000 (Invitrogen). The transfected cells were serum-starved for 6 hours and then the cultures were changed to medium containing 10\% FBS and 1\% ITS+ Premix reagent for 18 hours. Luciferase activity was then assayed.

Chromatin Immunoprecipitation (ChIP) Assay. C-28/I2 cells were treated with IL-1 $\beta$ at a concentration of $2 \mathrm{ng} / \mathrm{ml}$ in DMEM/F-12 supplemented with 10\% FBS and 1\% ITS+ Premix reagent and incubated for 24 hours. For immunoprecipitation, anti-C/EBP $\beta$ antibodies and normal rabbit IgG were used.

Over-expression in organ culture. Cartilage tissue was obtained from the intercondyle notch of 3 young adult patients who underwent anterior cruciate ligament (ACL) 
reconstruction. The cartilage tissue was cultured with an adenovirus expression vector for C/EBP $\beta$-LAP or LacZ control for 24 hours.

Statistical Analysis. For in vitro investigations, non-parametric comparisons were performed using a Mann-Whitney U-test. $\mathrm{P}$ values less than 0.05 were considered significant.

\section{RESULTS}

Colocalization of $\mathrm{C} / \mathrm{EBP} \beta$ and MMP-3 in synovium and cartilage from arthritis patients. We initially examined $\mathrm{C} / \mathrm{EBP} \beta$ and MMP-3 expression in synovial tissue and articular cartilage from OA and RA patients by immunohistochemistry. C/EBP $\beta$ and MMP-3 were expressed in OA and RA synovial tissue (figure 1). The distribution of $\mathrm{C} / \mathrm{EBP} \beta$ in synovial tissue was mainly in the synovial lining layer rather than in the sublining layer. MMP-3 had a similar distribution. In degenerative RA cartilage, C/EBP $\beta$ and MMP-3 were expressed in a proportion of the transitional and deep zones (figure 2). In mild OA cartilage, $\mathrm{C} / \mathrm{EBP} \beta$ and MMP-3 were predominantly distributed in the superficial zone. In areas of severe OA, chondrocytes that formed clusters in the deep zones were immunostained by $\mathrm{C} / \mathrm{EBP} \beta$ and MMP-3. Normal cartilage sections had little or no expression of $\mathrm{C} / \mathrm{EBP} \beta$ or MMP-3. VDIPEN epitopes were also positive in the peripheral area of cells expressing MMP-3 and C/EBP $\beta$ in both OA and RA cartilage. In addition, CEBP $\delta$ was expressed with a similar distribution in these tissues samples. The colocalization of $\mathrm{C} / \mathrm{EBP} \beta,-\delta$ and MMP-3 in arthritis synovium and cartilage suggests that $\mathrm{C} / \mathrm{EBP} \beta$ and $-\delta$ are involved in the regulation of MMP-3 expression.

Expression of C/EBPß and MMP-3 in cell lines after treatment with IL-1ß.

We set out to determine whether IL-1 $\beta$ could promote C/EBP $\beta$ protein and IL-6, MMP-3, MMP-13, ADAMTS-4, and ADAMTS-5 gene expression in cell lines. Western blots 
revealed that stimulation with IL-1 $\beta$ induced expression of both major isoforms (LAP; 36 $\mathrm{kDa}$ and LIP; $20 \mathrm{kDa}$ ) of C/EBP $\beta$ in nuclear extracts (figure S1A). Quantitative RT-PCR showed that MMP-3 and MMP-13 mRNA was strongly enhanced in cells treated with IL-1 $\beta$ (figure S1B). Since C/EBP $\beta$ is known to induce IL-6 expression in response to IL-1[31], we also confirmed the stimulation of IL-6 mRNA expression in these cells, which suggested the induced C/EBP $\beta$ is active in these cells. ADAMTS-5 was up-regulated approximately 2-fold in these cells. ADAMTS-4 was not significantly up-regulated in SW982 and C28/I2 cells, but was increased 3-fold in HFLS cells.

\section{Over-expression of C/EBPß stimulates expression of MMP-3, MMP-13 and}

ADAMTS-5. We next examined cells transfected with an adenovirus vector expressing C/EBP $\beta$-LAP or LacZ control for 24 hours. Western blots showed exogenous over-expression of $\mathrm{C} / \mathrm{EBP} \beta$-LAP in whole extracts isolated from transfected cells (figure 3A). The up-regulation of IL-6 expression was confirmed in all cells. The mRNA expression of MMP-3 and MMP-13 was also significantly increased in all cells. ADAMTS-5 mRNA expression was increased 5-fold by C/EBP $\beta$ over-expression, but ADAMTS-4 mRNA was not increased. In addition, ELISA analysis in the culture medium revealed the cells over-expressed CEBP $\beta$-LAP released more amount of total MMP-3 and IL-6 than that of control (figure 3B). Casein zymography revealed that MMP-3 was induced in an active form by the over-expression of $\mathrm{C} / \mathrm{EBP} \beta$ (figure $3 \mathrm{C}$ ).

\section{C/EBPß knockdown by siRNA reduced MMP-3 and ADAMTS-5 expression.} We next assayed siRNA transfected cells targeting C/EBP $\beta$ mRNA. Transfected cells were cultured with IL-1 $\beta$. Nuclear extracts and mRNA expression of C/EBP $\beta$ were effectively reduced by both siRNA-1 and siRNA-2 C/EBP $\beta$ transfection (figure 4A). C/EBP $\beta$ knockdown with siRNA-1 caused a significant decrease of IL-6 mRNA expression (figure 4B). MMP-3 mRNA expression was remarkably reduced in all cells. MMP-13 expression 
was repressed in C-28/I2 cells and HFLS cells. ADAMTS-5 expression was significantly reduced in C28/I2 cells. C/EBP $\beta$ knockdown with siRNA-2 caused similar results (data not shown). The knockdown of C/EBP $\beta$ by siRNA reduced the expression of IL-6 and these enzymes in a dose dependent manner (figure S2). We also performed experiments with CEBP $\delta$ knockdown. Cells transfected with the siRNA-CEBP $\delta$ showed reduction of IL-6 and MMP3 mRNA (figure S3).

\section{C/EBP $\beta$ functions as an activator of the MMP-3 and ADAMTS-5 promoter.} We further analyzed the in vitro promoter activity of MMP-3 and ADAMTS-5 using C28/I2 cells. A luciferase reporter gene construct containing 2011 bp from the human MMP-3 promoter or $2498 \mathrm{bp}$ from the human ADAMTS-5 promoter was co-transfected with the C/EBP $\beta$ pCMV-LAP expression vector into C28/I2 cells. Promoter activities for both MMP-3 and ADAMTS-5 were up-regulated in a dose-dependent manner (figure 5A). Similar promoter activity was exhibited in SW982 cells (data not shown). C/EBP expression vector also activated MMP-3 and ADAMTS-5 promoters in a dose dependent manner, whereas the stimulating effects were weaker than that of $\mathrm{C} / \mathrm{EBP} \beta$.

Localization of the C/EBPß binding site in the MMP-3 promoter. To identify the $\mathrm{C} / \mathrm{EBP} \beta$ responsive element in the MMP-3 promoter, deletion and mutation analysis was performed. We generated a series of 5'-promoter deletion constructs (figure 5B), which were co-transfected with C/EBP $\beta$ pCMV-LAP into C28/I2 cells. Construct p-del3 demonstrated reduced luciferase activity (figure $5 \mathrm{C}$ ). These results showed that the putative $\mathrm{C} / \mathrm{EBP} \beta$ binding site is located between $-224 \mathrm{bp}$ and $-56 \mathrm{bp}$ of the MMP-3 promoter.

To determine the core binding site, we performed site directed mutagenesis, which created two mutations changing GNAA into GNCC. Analysis of the sequence between $-224 \mathrm{bp}$ and $-56 \mathrm{bp}$ indicated the presence of three C/EBP $\beta$ consensus binding motifs $\mathrm{T}(\mathrm{T} / \mathrm{G}) \mathrm{NNGNAA}(\mathrm{T} / \mathrm{G})$. We created 3 single mutation constructs and 1 double 
mutation construct in the p-del2 MMP-3 promoter. The promoter activities of $\mathrm{p}$-del2-m3 and p-del2-D(m2+m3) equally decreased by $25 \%$, indicating that the core binding site of $\mathrm{C} / \mathrm{EBP} \beta$ is located between $-108 \mathrm{bp}$ and $-100 \mathrm{bp}$ of the human MMP-3 promoter (figure 5D). A ChIP assay was performed using primers in the human MMP-3 and ADAMTS-5 promoter sequences, which amplified sites including the $\mathrm{C} / \mathrm{EBP} \beta$ consensus binding motifs. This analysis indicated that $\mathrm{C} / \mathrm{EBP} \beta$ binds to the MMP-3 and the ADAMTS-5 promoter region in C28I2 cells treated with IL-1 $\beta$ (figure 5E).

\section{C/EBPß induces MMP-3 with a degrading activity in explants of cartilage}

tissue. We next used adenoviruses carrying LacZ or C/EBP $\beta$-LAP to infect explants of normal cartilage tissues. Immunohistochemical staining confirmed an increased expression of $\mathrm{C} / \mathrm{EBP} \beta$ induced by the infection (figure $6 \mathrm{~A}$ ). Over-expression of C/EBP $\beta$-LAP markedly induced MMP-3 expression in cartilage tissues. In addition, anti-VDIPEN-epitopes intensely stained cartilage tissues infected with C/EBP $\beta$-LAP (figure 6B). Furthermore, anti-NITEGE-epitopes, which are generated following cleavage by aggrecanases such as ADAMTS-4 and ADAMTS-5, also stained C/EBP $\beta$-LAP-infected cartilage (figure 6B). These results suggest that over-expression of $\mathrm{C} / \mathrm{EBP} \beta$ promotes the degradation of aggrecan by stimulating the expression of active proteolytic enzymes such as MMP-3, MMP-13 and ADAMTS-5.

\section{DISCUSSION}

In this study, we demonstrated that the transcription factor C/EBP $\beta$ promotes MMP-3 expression in arthritic synovial membrane and cartilage tissue. Alteration of MMP-3 expression by gain and loss of function of $\mathrm{C} / \mathrm{EBP} \beta$ was most significant, suggesting that $\mathrm{C} / \mathrm{EBP} \beta$ is one of the main regulators of MMP-3 expression. Furthermore, this study also suggests that $\mathrm{C} / \mathrm{EBP} \beta$ regulates, at least in part, ADAMTS-5, which is also a crucial enzyme 
in degrading cartilage in OA. These findings suggest that $\mathrm{C} / \mathrm{EBP} \beta$ plays crucial roles in cartilage degradation through production of various catabolic enzymes in synovium and cartilage in RA and OA. In addition, we performed experiments in relation to CEBP $\delta$. Promoter assay and treatment with siRNA for $\mathrm{C} / \mathrm{EBP} \delta$ indicated that $\mathrm{C} / \mathrm{EBP} \delta$ is also involved in cartilage degradation by production of IL-6, MMP-3 and ADAMTS-5, whereas the contribution of $\mathrm{C} / \mathrm{EBP} \delta$ may be weaker than that of $\mathrm{C} / \mathrm{EBP} \beta . \mathrm{C} / \mathrm{EBP} \delta$ may play compensatory role for $\mathrm{C} / \mathrm{EBP} \beta$ in the catabolic processes in arthritis.

In inflammatory arthritis, particularly in RA, synovitis is thought to be a key player in pathogenesis. In contrast, the pathogenesis of OA may originate from cartilage and the cartilage degradation may induce secondary synovitis. However, recently the concept of synovial inflammation contributing to OA pathology particularly in early disease has been emphasized.[4] Immunohistochemical staining in this study showed that C/EBP $\beta$ was expressed in synovial tissues regardless of arthritis type (RA or OA). These findings suggest that $\mathrm{C} / \mathrm{EBP} \beta$ is a common proinflammatory factor in arthritic synovial tissues, which profoundly affects degradation of cartilage. As previously described, MMP-3 is highly expressed in both RA and OA synovium, which is a potent activator of tissue procollagenases. Aforementioned in introduction, MMP-3 knock-out mice demonstrating the importance of this matrix-degrading enzyme in an animal model of OA.[22] However, the relevance of MMP-3 in RA is far to be clear since the same MMP-3 knock-out mice normally develop arthritis.[32] This report indicated that MMP-3 is one of important catabolic factors, whereas only inhibition of MMP-3 is insufficient to inhibit the cartilage degradation. Joint destruction results from multiple matrix-degrading enzymes such as other MMPs and ADAMTSs. MMP-13 and ADAMTS-5 also exist in the synovial tissue of arthritis.[33-35] Therefore, the regulation of these catabolic factors by $\mathrm{C} / \mathrm{EBP} \beta$ in the synovium may be important for the pathogenesis of RA and OA. 
In addition to the findings in synovium, we identified that $\mathrm{C} / \mathrm{EBP} \beta$ is involved in the expression of MMP-3, MMP-13 and ADAMTS-5 in chondrocytes. It is reported that MMP-3 is strongly expressed in early degenerative cartilage, while expression of MMP-3 is reduced in late stage OA. MMP-13 and ADAMTS-5 are up-regulated in late stage OA cartilage.[36] These observations raise the possibility that C/EBP $\beta$ function may depend on OA stage. Inflammatory signals might occur as a result of cartilage damage induced by other factors such as mechanical stress. The activation of C/EBP $\beta$ initiated by inflammatory signals in synovium and cartilage may subsequently mediate various catabolic processes including up-regulation of MMP-1, MMP-3, MMP-13 and ADAMTS-5. Activated C/EBP $\beta$ also mediates the phenotype change of chondrocytes into hypertrophic cells, which express MMP-13, vascular endothelial growth factor (VEGF) and type X collagen, as recent papers have reported.[37, 38] Therefore, regardless of pathogenesis, C/EBP $\beta$ plays crucial roles in degeneration of cartilage in OA. We suggest that C/EBP $\beta$ mediates MMP-3 activity in early disease via an inflammatory signal pathway. With progression of OA, C/EBP $\beta$ function may stimulate a different pathway involved in hypertrophic differentiation of chondrocytes and regulation of MMP-13 and ADAMTS-5.

Our data indicate that $\mathrm{C} / \mathrm{EBP} \beta$ regulates ADAMTS-5 expression particularly in chondrocytes. The molecular mechanism involving expression of ADAMTS-5 remains unclear. Examination of the human ADAMTS-5 promoter suggests that it is regulated by runt-related transcription factor-2 (RUNX2),[39] which is a protein known to be expressed in OA. RUNX2 is required for chondrocyte hypertrophy in the development of OA.[40] C/EBP $\beta$ also promotes hypertrophic differentiation of chondrocytes.[37] There is increasing evidence to suggest that C/EBP $\beta$ acts as a co-activator of RUNX2 on several down-stream targets. Indeed, the osteocalcin promoter is up-regulated by co-activation of C/EBP $\beta$ and RUNX2.[12] We found potential C/EBP $\beta$ binding motifs in the ADAMTS-5 promoter 
(-1517 to -1509$)$, which is located next to the RUNX2 responsive motifs previously reported.[39] In fact, the CHIP assay showed that C/EBP $\beta$ binds the ADAMTS-5 promoter region between $-1648 \mathrm{bp}$ and $-1365 \mathrm{bp}$. Therefore, it is conceivable that $\mathrm{C} / \mathrm{EBP} \beta$ interacts with RUNX2 and synergistically activates ADAMTS-5 expression in arthritis leading to degradation of cartilage.

In conclusion, $\mathrm{C} / \mathrm{EBP} \beta$ is considered to play two major roles in arthritis. One role is the regulation of an inflammatory signal pathway. C/EBP $\beta$ regulates MMP-1, MMP-3, MMP-13 and partially ADAMTS-5 in synovium and chondrocytes in arthritis during the process of inflammation. The other role promotes hypertrophic differentiation of chondrocytes. MMP-13 is a major collagenase in arthritis and is a hypertrophic marker of chondrocytes. Therefore, C/EBP $\beta$ may regulate MMP-3, MMP-13 and ADAMTS-5 in the process of hypertrophy. The data presented here indicate that $\mathrm{C} / \mathrm{EBP} \beta$ mediates multiple factors, which reinforces the idea that $\mathrm{C} / \mathrm{EBP} \beta$ is one of the most important inflammatory signals in arthritis.

\section{ACKNOWLEDGEMENT}

We thank Dr. John S. Mort, Shriners Hospital for Children and McGill University, Montreal, Canada for providing antibodies to the aggrecan cleavage epitope.

We thank Dr. Hiroshi Sakaue for providing the adenovirus expression vector for C/EBP-LAP and LacZ.

This work was supported in part by a Grant-in-Aid in Scientific Research (No. 21591948, 211160) from the Japan Society for the Promotion of Science and Research Grant for Intractable Diseases from the Ministry of Health and Welfare of Japan. 
Licence for Publication

The Corresponding Author has the right to grant on behalf of all authors and does grant on behalf of all authors, an exclusive licence (or non exclusive for government employees) on a worldwide basis to the BMJ Publishing Group Ltd to permit this article (if accepted) to be published in ARD and any other BMJPGL products and sublicences such use and exploit all subsidiary rights, as set out in our licence. 


\section{REFERENCES}

1. Farahat MN, Yanni G, Poston R, et al. Cytokine expression in synovial membranes of patients with rheumatoid arthritis and osteoarthritis. Ann Rheum Dis. 1993;52:870-875.

2. Benito MJ, Veale DJ, FitzGerald O, et al. Synovial tissue inflammation in early and late osteoarthritis. Ann Rheum Dis. 2005;64:1263-1267.

3. Otero M, Goldring MB. Cells of the synovium in rheumatoid arthritis. Chondrocytes. Arthritis Res Ther. 2007;9:220.

4. Bondeson J, Blom AB, Wainwright $\mathrm{S}$, et al. The role of synovial macrophages and macrophage-produced mediators in driving inflammatory and destructive responses in osteoarthritis. Arthritis Rheum. 2010;62:647-657.

5. Cao Z, Umek RM, McKnight SL. Regulated expression of three C/EBP isoforms during adipose conversion of 3T3-L1 cells. Genes Dev. 1991;5:1538-1552.

6. Ramji DP, Foka P. CCAAT/enhancer-binding proteins: structure, function and regulation. Biochem J. 2002;365:561-575.

7. Pope RM, Lovis R, Mungre S, et al. C/EBP beta in rheumatoid arthritis: correlation with inflammation, not disease specificity. Clin Immunol. 1999;91:271-282.

8. Nishioka K, Ohshima S, Umeshita-Sasai M, et al. Enhanced expression and DNA binding activity of two CCAAT/enhancer-binding protein isoforms, C/EBPbeta and C/EBPdelta, in rheumatoid synovium. Arthritis Rheum. 2000;43:1591-1596.

9. Massaad C, Paradon M, Jacques C, et al. Induction of secreted type IIA phospholipase A2 gene transcription by interleukin-1beta. Role of C/EBP factors. $J$ Biol Chem. 2000;275:22686-22694. 
10. Thomas B, Berenbaum F, Humbert L, et al. Critical role of C/EBPdelta and $\mathrm{C} / \mathrm{EBPb}$ ta factors in the stimulation of the cyclooxygenase-2 gene transcription by interleukin-1beta in articular chondrocytes. Eur J Biochem. 2000;267:6798-6809.

11. Greenwel P, Tanaka S, Penkov D, et al. Tumor necrosis factor alpha inhibits type I collagen synthesis through repressive CCAAT/enhancer-binding proteins. Mol Cell Biol. 2000;20:912-918.

12. Gutierrez S, Javed A, Tennant DK, et al. CCAAT/enhancer-binding proteins (C/EBP) beta and delta activate osteocalcin gene transcription and synergize with Runx 2 at the C/EBP element to regulate bone-specific expression. J Biol Chem. 2002;277:1316-1323.

13. Okazaki $\mathrm{K}, \mathrm{Li} \mathrm{J}, \mathrm{Yu} \mathrm{H}$, et al. CCAAT/enhancer-binding proteins beta and delta mediate the repression of gene transcription of cartilage-derived retinoic acid-sensitive protein induced by interleukin-1 beta. J Biol Chem. 2002;277:31526-31533.

14. Raymond L, Eck S, Mollmark J, et al. Interleukin-1 beta induction of matrix metalloproteinase-1 transcription in chondrocytes requires ERK-dependent activation of CCAAT enhancer-binding protein-beta. J Cell Physiol. 2006;207:683-688.

15. Hayashida M, Okazaki K, Fukushi J, et al. CCAAT/enhancer binding protein beta mediates expression of matrix metalloproteinase 13 in human articular chondrocytes in inflammatory arthritis. Arthritis Rheum. 2009;60:708-716.

16. Malfait AM, Liu RQ, Ijiri K, et al. Inhibition of ADAM-TS4 and ADAM-TS5 prevents aggrecan degradation in osteoarthritic cartilage. $J$ Biol Chem. 2002; 277:22201-22208.

17. Song RH, Tortorella MD, Malfait AM, et al. Aggrecan degradation in human articular cartilage explants is mediated by both ADAMTS-4 and ADAMTS-5. Arthritis Rheum. 2007;56:575-585. 
18. Okada Y, Shinmei M, Tanaka O, et al. Localization of matrix metalloproteinase 3 (stromelysin) in osteoarthritic cartilage and synovium. Lab Invest. 1992;66:680-690.

19. Okada $\mathrm{Y}$, Takeuchi $\mathrm{N}$, Tomita $\mathrm{K}$, et al. Immunolocalization of matrix metalloproteinase 3 (stromelysin) in rheumatoid synovioblasts (B cells): correlation with rheumatoid arthritis. Ann Rheum Dis. 1989;48:645-653.

20. Okada Y, Nagase H, Harris ED, Jr. A metalloproteinase from human rheumatoid synovial fibroblasts that digests connective tissue matrix components. Purification and characterization. J Biol Chem. 1986;261:14245-14255.

21. Ito A, Nagase H. Evidence that human rheumatoid synovial matrix metalloproteinase 3 is an endogenous activator of procollagenase. Arch Biochem Biophys. 1988;267:211-216.

22. Blom AB, van Lent PL, Libregts $\mathrm{S}$, et al. Crucial role of macrophages in matrix metalloproteinase-mediated cartilage destruction during experimental osteoarthritis: involvement of matrix metalloproteinase 3. Arthritis Rheum. 2007;56:147-157.

23. Yamanaka H, Matsuda Y, Tanaka M, et al. Serum matrix metalloproteinase 3 as a predictor of the degree of joint destruction during the six months after measurement, in patients with early rheumatoid arthritis. Arthritis Rheum. 2000;43:852-858.

24. Lohmander LS, Brandt KD, Mazzuca SA, et al. Use of the plasma stromelysin (matrix metalloproteinase 3) concentration to predict joint space narrowing in knee osteoarthritis. Arthritis Rheum. 2005;52:3160-3167.

25. Arnett FC, Edworthy SM, Bloch DA, et al. The American Rheumatism Association 1987 revised criteria for the classification of rheumatoid arthritis. Arthritis Rheum. 1988; $31: 315-324$

26. Mort JS, Buttle DJ. The use of cleavage site specific antibodies to delineate protein processing and breakdown pathways. Mol Pathol. 1999;52:11-18. 
27. Sztrolovics R, Alini M, Roughley PJ, et al. Aggrecan degradation in human intervertebral disc and articular cartilage. Biochem J. 1997;326:235-241.

28. Sakaue H, Konishi M, Ogawa W, et al. Requirement of fibroblast growth factor 10 in development of white adipose tissue. Genes Dev. 2002;16:908-912.

29. Hirai Y, Radisky D, Boudreau R, et al. Epimorphin mediates mammary luminal morphogenesis through control of C/EBPbeta. J Cell Biol. 2001;153:785-794.

30. Oelgeschlager M, Nuchprayoon I, Luscher B, et al. C/EBP, c-Myb, and PU.1 cooperate to regulate the neutrophil elastase promoter. Mol Cell Biol. 1996;16:4717-4725.

31. Akira S, Isshiki H, Sugita T, et al. A nuclear factor for IL-6 expression (NF-IL6) is a member of a C/EBP family. EMBO J. 1990;9:1897-1906.

32. Mudgett JS, Hutchinson NI, Chartrain NA, et al. Susceptibility of stromelysin 1-deficient mice to collagen-induced arthritis and cartilage destruction. Arthritis Rheum. 1998;41:110-121.

33. Marini S, Fasciglione GF, Monteleone G, et al. A correlation between knee cartilage degradation observed by arthroscopy and synovial proteinases activities. Clin Biochem. 2003;36:295-304.

34. Smeets TJM, Barg EC, Kraan MC, et al. Analysis of the cell infiltrate and expression of proinflammatory cytokines and matrix metalloproteinases in arthroscopic synovial biopsies: comparison with synovial samples from patients with end stage, destructive rheumatoid arthritis. Ann Rheum Dis. 2003;62:635-638.

35. Vankemmelbeke MN, Holen I, Wilson AG, et al. Expression and activity of ADAMTS-5 in synovium. Eur J Biochem. 2001;268:1259-1268.

36. Bau B, Gebhard PM, Haag J, et al. Relative messenger RNA expression profiling of collagenases and aggrecanases in human articular chondrocytes in vivo and in vitro. Arthritis Rheum. 2002;46:2648-2657. 
37. Hirata M, Kugimiya F, Fukai A, et al. C/EBPbeta Promotes transition from proliferation to hypertrophic differentiation of chondrocytes through transactivation of $\mathrm{p} 57$. PLoS One. 2009;4:e4543.

38. Tsuchimochi K, Otero M, Dragomir CL, et al. GADD45beta enhances Col10a1 transcription via the MTK1/MKK3/6/p38 axis and activation of C/EBPbeta-TAD4 in terminally differentiating chondrocytes. J Biol Chem. 2010;285:8395-8407.

39. Thirunavukkarasu K, Pei Y, Wei T. Characterization of the human ADAMTS-5 (aggrecanase-2) gene promoter. Mol Biol Rep. 2007;34:225-231.

40. Kamekura S, Kawasaki Y, Hoshi K, et al. Contribution of runt-related transcription factor 2 to the pathogenesis of osteoarthritis in mice after induction of knee joint instability. Arthritis Rheum. 2006;54:2462-2470.

\section{FIGURE LEGENDS}

Figure 1. Expression and distribution of $\mathrm{C} / \mathrm{EBP} \beta, \mathrm{C} / \mathrm{EBP} \delta, \mathrm{MMP}-3$ in arthritic synovium by immunohistochemistry. A, Immunohistochemistry of OA synovium. B, RA synovium. Synovium sections were stained with hematoxylin counterstain. IgG; staining with normal IgG antibodies, C/EBP $\boldsymbol{\beta}$; anti-C/EBP $\beta$ antibodies, $\mathbf{C / E B P \delta}$; anti-C/EBP $\delta$ antibodies, MMP-3; anti-MMP-3 antibodies in synovium. Original magnification $200 \times$ in A and B, 
scale bar, $100 \mu \mathrm{m} . \mathrm{C} / \mathrm{EBP}=\mathrm{CCAAT} /$ enhancer-binding protein; $\mathrm{MMP}=$ matrix metalloproteinase; $\mathrm{RA}=$ rheumatoid arthritis; $\mathrm{OA}=$ osteoarthritis.

Figure 2. Expression and distribution of $\mathrm{C} / \mathrm{EBP} \beta, \mathrm{C} / \mathrm{EBP} \delta, \mathrm{MMP}-3$ and VDIPEN in arthritic articular cartilage by immunohistochemistry. VDIPEN; anti-VDIPEN (a metalloproteinase-generated neoepitope) antibodies. Immunohistochemistry were performed in OA normal cartilage, mild OA cartilage, severe OA cartilage, RA cartilage. Cartilage sections were stained with methyl green counterstain. Original magnification $200 \times$, scale bar, $100 \mu \mathrm{m}$.

Figure 3. A, Effect of C/EBP $\beta$ over-expression on IL-6, MMPs, and ADAMTS expression in cells. SW982, C28/I2 and HFLS cells were transfected with adenovirus expression vector for C/EBP $\beta$-LAP or LacZ (negative control) and cultured for 24 hours. Whole cell extracts isolated from transfected cells were assayed by western blotting to confirm exogenous C/EBP $\beta$-LAP expression. Over-expression of C/EBP $\beta$-LAP stimulates IL-6, MMP-3, MMP-13, and ADAMTS-5 mRNA expression as investigated by quantitative real time RT-PCR in three cell lines. IL-6 = interleukin-6; ADAMTS $=$ a disintegrin and metalloproteinase with thrombospondin type 1 motif; HFLS = human fibroblast like synoviocytes. ${ }^{*} \quad \mathrm{p}<0.05$ versus control; Mann-Whitney U test.

B, Enzyme-linked immunosorbent assay (ELISA) for total MMP-3 and IL-6 with conditioned medium from C28/I2 or SW982 cells transfected with adenovirus expression vector for LacZ or LAP. Total MMP-3 and IL-6 were detected in cultured medium for 72 hours and 48 hours, respectively. * $\mathrm{p}<0.05$ versus control; Mann-Whitney U test. 
C, Casein zymography for MMP-3 with conditioned medium from SW982 or C28/I2 cells transfected with adenovirus expression vector for LacZ or LAP and cultured for 72 hours.

Figure 4. Effect of C/EBP $\beta$ knockdown on IL-6, MMPs, and ADAMTS expression in cells. Small interference RNA (siRNAs) targeting $\mathrm{C} / \mathrm{EBP} \beta$ or a negative control siRNA were transfected into SW982, HFLS and C28/I2 cells. Transfected cells were cultured with or without $10 \mathrm{ng} / \mathrm{ml} \mathrm{IL-1 \beta}$ for 24 hours, $10 \mathrm{ng} / \mathrm{ml} \mathrm{IL-1} \beta$ for 24 hours, $2 \mathrm{ng} / \mathrm{ml} \mathrm{IL-1} \beta$ for 5 hours, respectively. A, Effectiveness of $\mathrm{C} / \mathrm{EBP} \beta$ knockdown was ascertained by western blots and quantitative RT-PCR in three cell lines. B, RNA from cells transfected with control siRNA or siRNAs specific for C/EBP $\beta$ were analyzed for alterations in IL-6, MMP-3, MMP-13, ADAMTS-4, and ADAMTS-5 gene expression by quantitative RT-PCR. Expression levels are presented relative to cells transfected with control siRNA. ${ }^{*} \mathrm{p}<0.05$ versus control; Mann-Whitney U test.

Figure 5. A, Transactivation of the human MMP-3 promoter or human ADAMTS-5 promoter by $\mathrm{C} / \mathrm{EBP} \beta$ or $\mathrm{C} / \mathrm{EBP} \delta$. The 2011 bp MMP-3 or the 2498 bp ADAMTS-5 promoter-luciferase reporter vectors were co-transfected into C28/I2 cells with pCMV-LAP or $\mathrm{pMSV}-\mathrm{C} / \mathrm{EBP} \delta(0,0.1,0.4,0.8$, and $1.2 \mu \mathrm{g})$. The renilla luciferase normalization vector expressing and GFP, which was used to adjust the total amount of transfected DNA. Relative luciferase activity was assayed 24 hours post-transfection. B, Deletion promoter analysis of the human MMP-3 promoter. Schematic of the 5'-deletion constructs of the MMP-3 promoter (p-del), which were subcloned into the pGL-4.10 [luc2] vector. C, The MMP-3 promoter deletion constructs were co-transfected with pCMV-LAP or GFP into C28/I2 cells. Relative luciferase activity was assayed 24 hours post-transfection. D, Site-directed mutagenesis of the human MMP-3 promoter and luciferase reporter assay. The promoter 
deletion construct, $\mathrm{p}$-del2, contains three potential binding sites for C/EBP $\beta$. A 2 bp mutation $(\mathrm{m})$ was made at one site $(\mathrm{m} 1,-\mathrm{m} 2,-\mathrm{m} 3)$ or at both sites $(\mathrm{Dm}=$ double mutation $)$, D $(\mathrm{m} 2+\mathrm{m} 3)$, of the p-del2 construct. Mutant constructs were co-transfected with pCMV-LAP or GFP into C28/I2 cells and the relative luciferase activity was assayed 24 hours post-transfection. $\mathrm{pCMV-LAP}=$ an expression vector of rat $\mathrm{C} / \mathrm{EBP} \beta$-LAP. $\mathrm{pMSV}-\mathrm{C} / \mathrm{EBP} \delta=$ an expression vector of rat $\mathrm{C} / \mathrm{EBP} \delta . \mathrm{GFP}=$ green fluorescent protein. $\mathbf{E}$, $\mathrm{C} / \mathrm{EBP} \beta$ binds to the human MMP-3 and ADAMTS-5 promoter in C28/I2 cells. After treatment with IL-1 $\beta$ for 24 hours, a Chromatin immunoprecipitation assay (ChIP) was performed using $\mathrm{C} / \mathrm{EBP} \beta$ specific antibodies or control IgG. The C/EBP $\beta$ bound MMP-3 promoter or C/EBP $\beta$-ADAMTS-5 promoter complex were amplified by semi-quantitative RT-PCR with primers for the MMP-3 promoter (from -214 bp to $+19 \mathrm{bp}$ ), a negative MMP-3 control (from -1727 bp to $-1487 \mathrm{bp}$ ), the ADAMTS-5 promoter (from -1648 bp to -1365 bp), or a negative ADAMTS-5 control (from -2044 bp to $-1887 \mathrm{bp}$ ). Similar concentrations of input DNA was used before immunoprecipitation and contained random DNA sequence. The PCR products were amplified for 33 cycles.

Figure 6. Normal cartilage was transfected with control (LacZ) or CMV-LAP (C/EBP $\beta)$ for 24 hours. Organ cultured cartilage tissues were immunostained. A, anti-IgG, C/EBP $\beta$, and MMP-3 antibodies, B, anti-VDIPEN (a mettaloproteinase-generated neoepitope) epitope and NITEGE (an aggrecan C-terminal neoepitope) epitope antibodies. Cartilage sections were stained with methyl green counterstain. Original magnification $200 \times$ in A, scale bar, $100 \mu \mathrm{m}$ and $400 \times$ in $\mathbf{B}$, scale bar, $50 \mu \mathrm{m}$. 
Figure 1

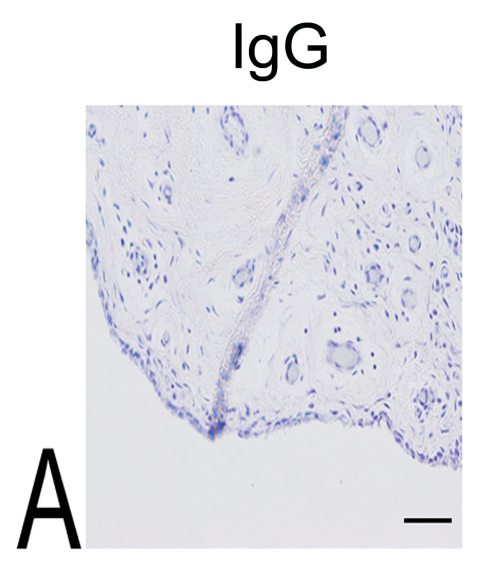

CEBP $\beta$
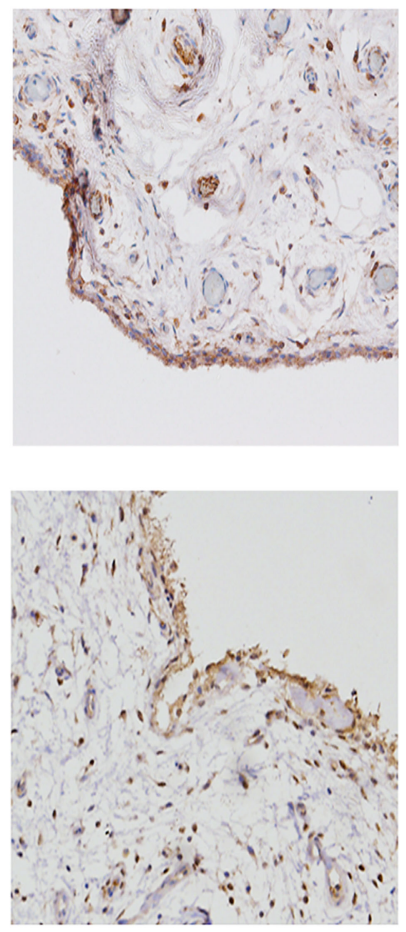

MMP-3
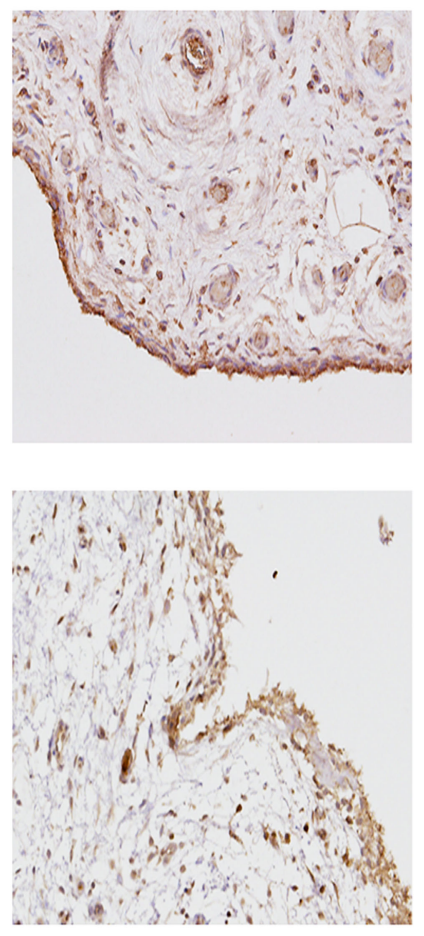

CEBP $\delta$
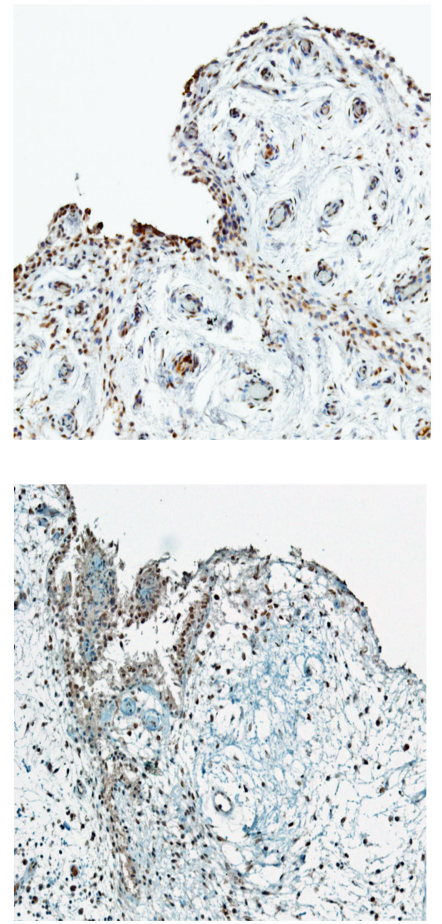
Figure 2

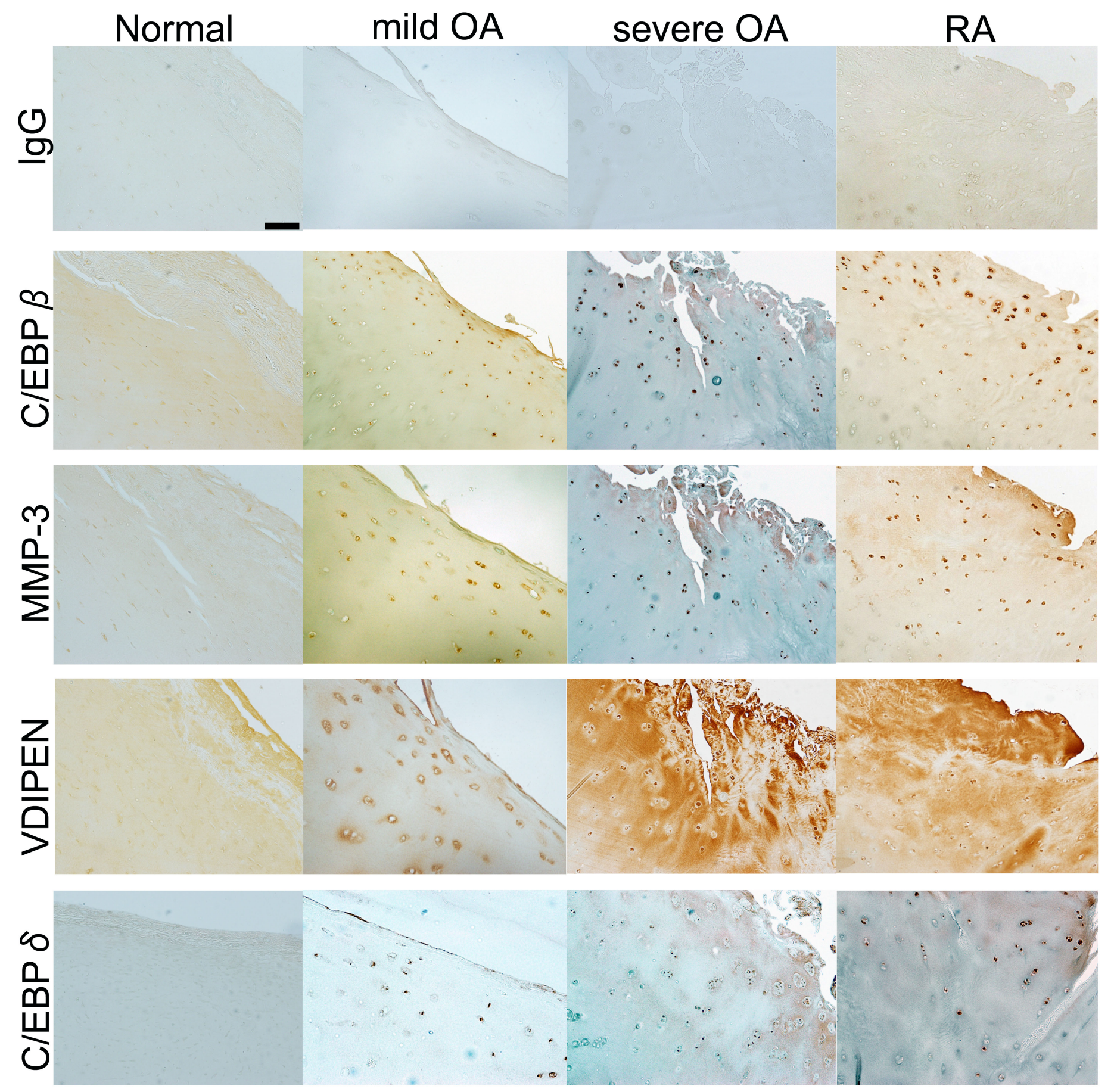


Figure 3

A
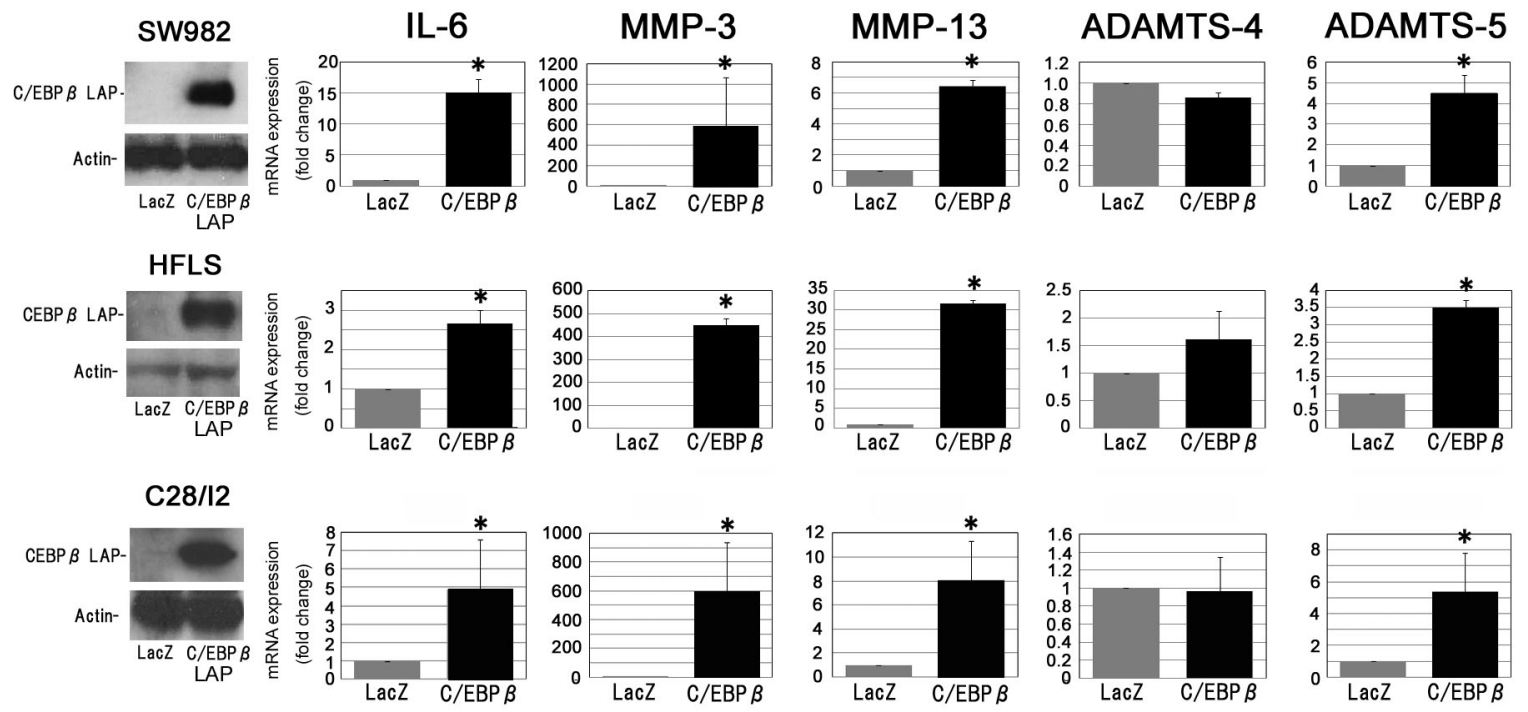

B
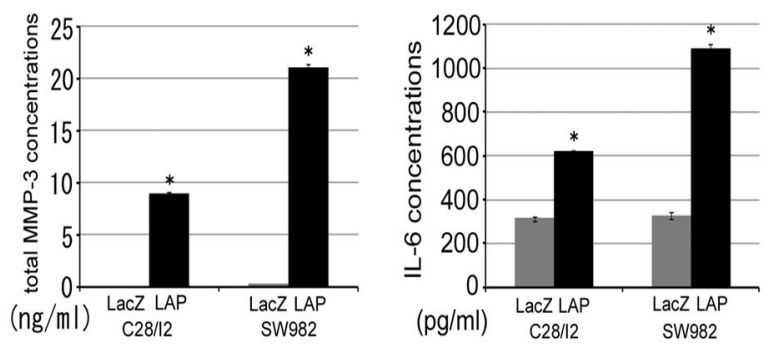

C

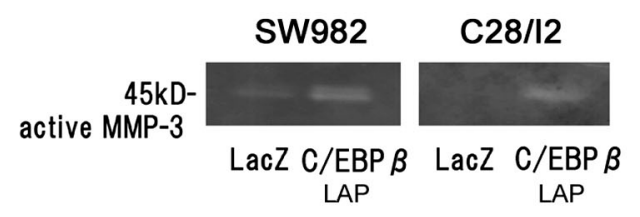


Figure 4
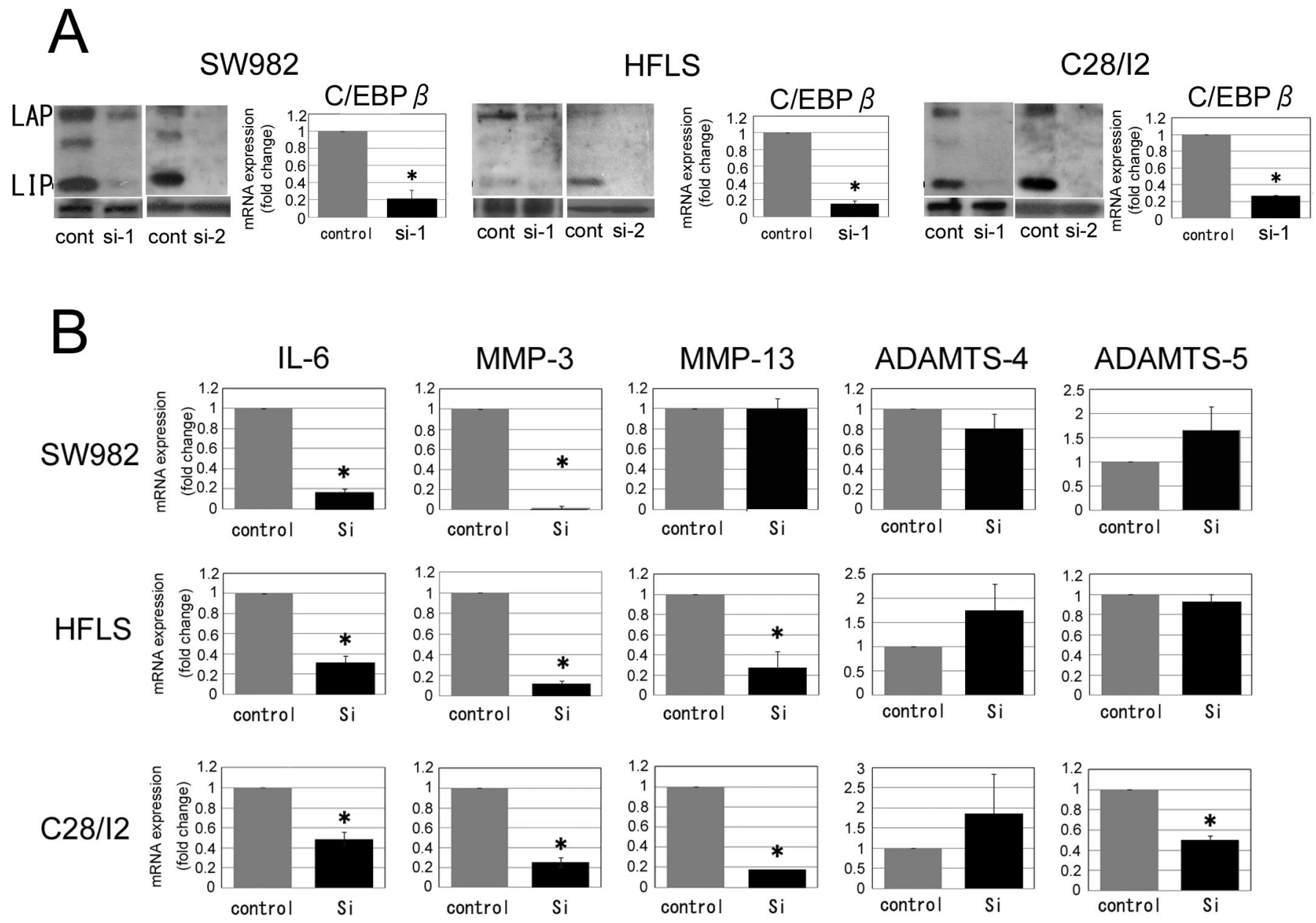
Figure 5

A

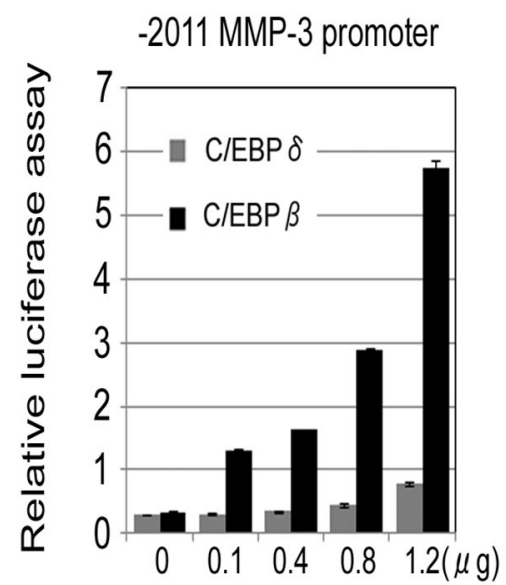

C

$\mathrm{C} 28 / 12$

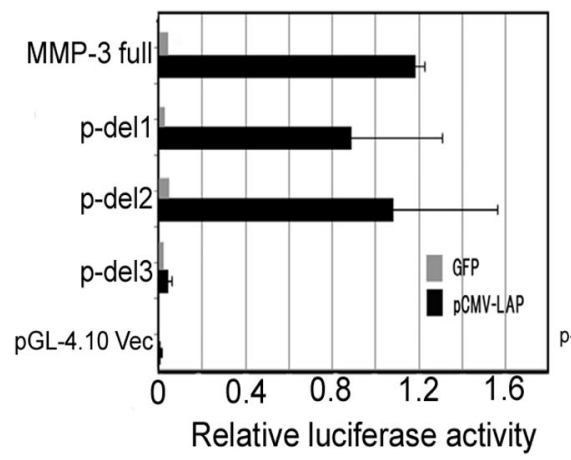

-1768bp ADAMTS-5 promoter

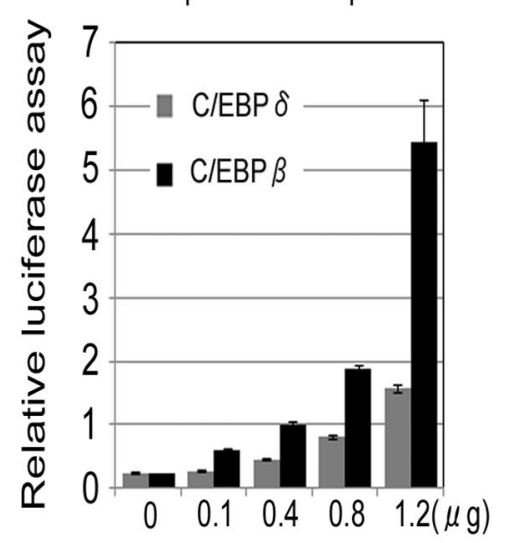

$\mathrm{C} 28 / 12$

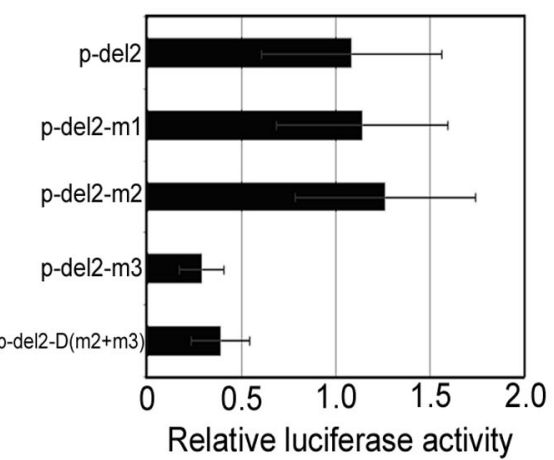

B

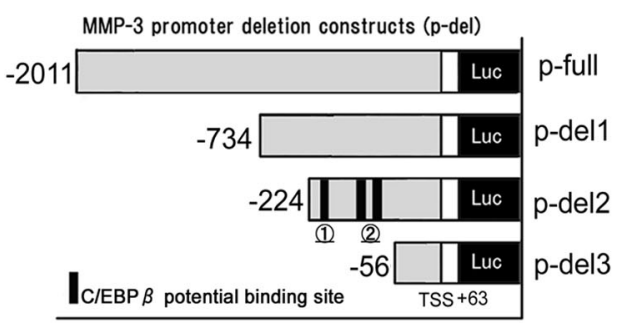

WT(1) GTTGCCTTGCAAAATTGGG

$\mathrm{m} 1$ GTTGCCTTGCCCAATTGGG

WT(2) GAATTTGGAATGTTTGGAAATGG

$\mathrm{m} 2$ GAATTTGGCCTGTTTGGAAATGG

m3 GAATTTGGAATGTTTGGACCTGG

$D(m 2+m 3)$ GAATTTGGCCTGTTTGGACCTGG

E

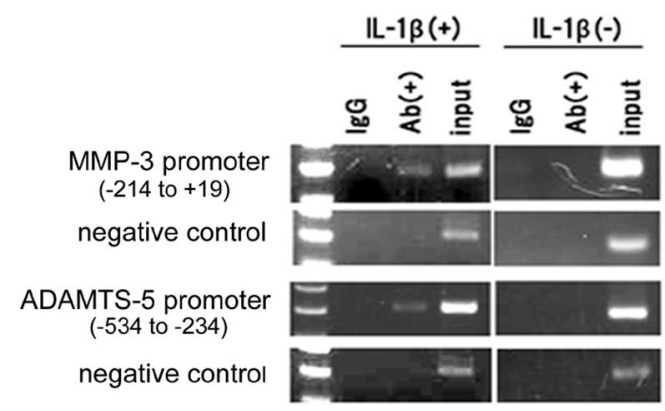


Figure 6

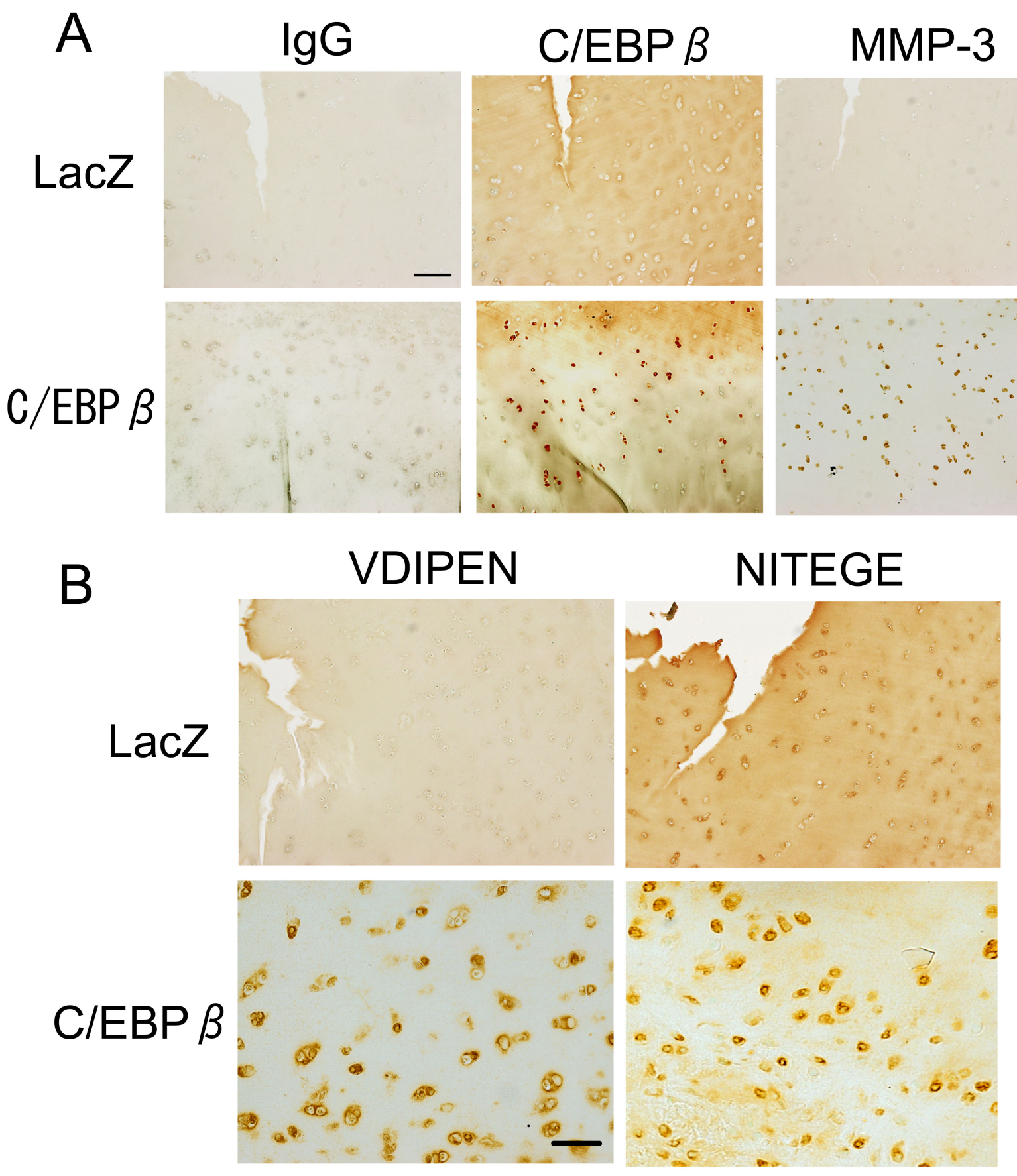

